\title{
BioNames: linking taxonomy, texts, and trees
}

BioNames is a web database of taxonomic names for animals, linked to the primary literature and, wherever possible, to phylogenetic trees. It aims to provide a taxonomic "dashboard" where at a glance we can see a summary of the taxonomic and phylogenetic information we have for a given taxon and hence provide a quick answer to the basic question "what is this taxon?" BioNames combines classifications from the Global Biodiversity Information Facility (GBIF) and GenBank, images from the Encyclopedia of Life (EOL), animal names from the Index of Organism Names (ION), and bibliographic data from multiple sources including the Biodiversity Heritage Library (BHL) and CrossRef. The user interface includes display of full text articles, interactive timelines of taxonomic publications, and zoomable phylogenies. It is available at http://bionames.org. 
1 Roderic D. M. Page

2 Institute of Biodiversity, Animal Health and Comparative Medicine

3 College of Medical, Veterinary and Life Sciences

4 Graham Kerr Building

5 University of Glasgow

6 Glasgow G12 8QQ, UK

7 Telephone: +441413304778

8 Email: Roderic.Page@glasgow.ac.uk 


\section{Introduction}

10 Large-scale digitisation of biodiversity data is underway on at least three broad fronts. The first,

11 and perhaps the only category that is genuinely "born digital" is DNA sequencing (Benson et al.

12 2012). DNA barcoding (Hebert 2003) and, more recently, "metabarcoding" (Taberlet et al. 2012)

13 is generating a flood of sequence data, much of it tied to a specific place and time. The contents

14 of natural history collections are being digitised (Baird 2000), both the specimens themselves

15 (Blagoderov et al. 2012) and metadata about those specimens. The latter is being aggregated by

16 the Global Biodiversity Information Facility (GBIF; http://data.gbif.org) to provide an overview

17 of the spatial distribution of life on Earth. Much of the biological literature is similarly being converted from physical to digital form, most notably by the-Biodiversity Heritage Library (BHL; http://www.biodiversitylibrary.org)(Pilsk et al. 2010). Taxonomic publication is becoming increasingly digital through rise of "mega" journals such as Zootaxa (http://www.mapress.com/zootaxa/) (Zhang, 2006), and semantically enriched journals such as ZooKeys (http://www.pensoft.net/journals/zookeys/) (Penev et al. 2010).

23 The increasing use of sequence data has made taxonomic relationships readily computable (e.g.,

24 by building phylogenetic trees). Yet many DNA sequences are disconnected from classical taxonomy because they the associated taxa lack formal taxonomic names (Page 2011c; Parr et al. 2012). Barcoding has been responsible for a massive influx of these "dark taxa" into the sequence

27 databases (Page 2011c). Many of these unnamed barcode taxa have since been suppressed by

28 GenBank. But even without the barcoding sequences, dark taxa have been steadily increasing in

29 number in recent years. Names may have a special place in the hearts of taxonomists (Patterson et

30 al. 2010), but the pace of biodiversity discovery is outstripping our ability to put names on taxa, 
31 as evidenced by the rise of dark taxa in GenBank. There are increasing calls to adopt less formal

32 taxonomic naming schemes (Schindel and Miller 2010), or to focus on describing biodiversity

33 without necessarily naming it (Deans et al. 2012; Maddison et al. 2012). A significant challenge

34 will be determining whether these dark taxa represent newly discovered taxa, or come from

35 known taxa but have not been identified as such (Hibbett and Glotzer 2011; Nagy et al. 2011).

36 The vision of "Biodiversity Information on Every Desktop" (Edwards 2000) (perhaps updated to

37 "biodiversity on every device") rests on our ability to not only digitise life (and the documents we

38 have generated during centuries of cataloguing and studying biodiversity) but also to integrate the

39 wealth of data emerging from sequencing machines and optical scanners. There are numerous

40 points of contact between these different efforts, such as specimen codes, bibliographic

41 identifiers, and GenBank accession numbers (Page 2008a; -2010). Figure 1 shows a simplified

42 model of the core entities that make up taxonomy and related disciplines (e.g., systematics). The

43 diagram is not meant to be exhaustive, nor does it attempt to rigorously define relationships in

44 terms of one or more available ontologies. Instead, it simply serves as a way to visualise the links

45 between taxon names, the publications (and authors and journals) where those names first appear,

46 the application of those names to taxa, and data associated with those taxa (e.g., DNA sequence-

47 based phylogenies).

48 Despite the wealth of possible connections between biodiversity data objects, the most commonly

49 shared identifier that spans sequences, specimens, and publications remains the taxonomic name

50 (Sarkar 2007; Patterson et al. 2010). We rely on names to integrate data, despite the potential

51 ambiguity in what a given taxonomic name "means" (Kennedy et al. 2005; Franz and Cardona-

52 Duque 2013). Unfortunately, it is often difficult to obtain information on a taxonomic name,

53 either to track its origins and subsequent use, or to verify that it has been correctly used. Typically 
54 when taxonomic literature is cited in databases, it is typically as a text string with no link to the

55 growing corpus of digitised literature. Hence taxonomic databases are little more than online

56 collections of $5 \times 3$ index cards, technology taxonomy's founding father Linnaeus himself

57 pioneered (Müller-Wille \& Charmantier 2012). Ideally, for any given taxon name we should be

58 able to see the original description, track the fate of that name through successive revisions, and

59 see other related literature. At present this is usually difficult and tedious almost impossible-to do,

60 even in well studied taxa.

\section{EOL Challenge}

62 In response to the Encyclopedia of Life (EOL) Computational Data Challenge

63 (http://eol.org/info/323) I constructed BioNames (http://bionames.org) (Page 2012). Its goal is to

64 create a database of taxonomic names for animals linked to the primary literature and, wherever

65 possible, to phylogenetic trees. Using existing globally unique identifiers for taxonomic names,

66 concepts, publications, and sequences rather than cryptic text strings (for example, abbreviated

67 bibliographic citations) simplifies the task of linking — we can rely on exact matching of

68 identifiers rather than approximate matching between names for what may or may not be the

69 same entity. This is particularly relevant once we start to aggregate information from different

70 databases, where the same information (e.g., a publication) may be represented by different

71 strings. Furthermore, if we use existing identifiers we increase the potential to connect to other

72 databases (Page 2008a). This paper outlines how BioNames was built, describes the user

73 interface, and discusses future plans. 


\section{Materials \& Methods}

75 BioNames integrates data on taxonomic names and classifications, literature, and phylogenies

76 from a variety of sources. Given the inevitable differences in how different databases treat the

77 same data (as well as internal inconsistencies within individual databases), considerable effort

78 must be spent cleaning and reconciling data. Much of this process involves mapping "strings" to

79 "things" (Bollacker et al. 2008), or more precisely, mapping strings to identifiers for things.

\section{Taxon names}

81 At present the taxonomic scope of BioNames is restricted to names covered by the International

82 Code of Zoological Nomenclature (animals and those eukaryotes not covered by the International

83 Code of Nomenclature for algae, fungi, and plants). Taxonomic names were obtained from the

84 Index of Organism Names (ION; http://www.organismnames.com). Each name in ION has a Life

85 Science Identifier (LSID) (Martin et al. 2005) which uniquely identifies that name. LSIDs can be

86 dereferenced to return metadata in Resource Description Framework format (RDF) (Page 2008b).

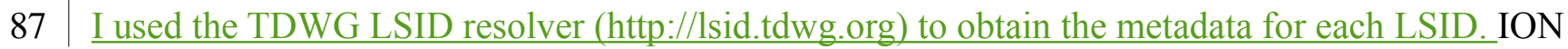

88 LSIDs provide basic information on a taxonomic name using the TDWG Taxon Name LSID

89 Ontology (http://rs.tdwg.org/ontology/voc/TaxonName), in many cases including bibliographic

90 details for the publication where the name first appeared (Fig. 2).

91 The publication in which the name first appeared is listed in the contents of the "PublishedIn"

92 property. In the example in Figure 2 this is the string "Description of a new species of

93 Pinnotheres, and redescription of P. novaezelandiae (Brachyura: Pinnotheridae). New Zealand

94 Journal of Zoology, 10(2) 1983: 151-162. 158 (Zoological Record Volume 120)". I used regular 
95

96 pagination), and then attempted to locate the corresponding reference in an external database (see 97 below).

\section{Bibliographic identifiers}

99 When populating BioNames every effort has been made to map each bibliographic string to a

100 corresponding identifier, such as a Digital Object identifier (DOI). For the example in Figure 2,

101 the citation string "Description of a new species of Pinnotheres, and redescription of P.

102 novaezelandiae (Brachyura: Pinnotheridae). New Zealand Journal of Zoology, 10(2) 1983: 151-

103 162. 158 (Zoological Record Volume 120)" corresponds to the article with the DOI

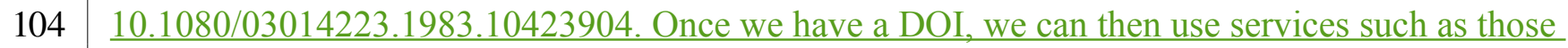

105

106

107

108 While DOIs are the best-known bibliographic identifier, there are several others that are relevant

109 to the taxonomic literature (Page 2009). DOIs are themselves based on Handles

110 (http://hdl.handle.net), an identifier widely used by digital repositories such as DSpace (Smith et

111 al. 2003). A number of journals, such as the Bulletins and Novitates of the American Museum of

112 Natural History are available in DSpace repositories and consequently have Handles. Other major

113 archives such as JSTOR (http://www.jstor.org/) and the Japanese National Institute of Informatics

114 (CiNii; http://ci.nii.ac.jp/) have their own unique identifiers (typically integer numbers that are

115 part of a URL). 
116 Having a variety of identifiers can complicate the task of finding existing identifiers for a

117 particular publication. Whereas for some identifiers, such as DOIs , $_{2}$ and CiNii NAIDs (National

118 Institute of Informatics Article IDs), and BioStor reference ids there are search tools (e.g.,

119 http://search.crossref.org) or OpenURL resolvers for this task (Van de Sompel \& Beit-Arie 2001)_

120 (e.g., http://biostor.org/openurl), for other identifiers there may be no obvious way to find the

121 identifier other than by using a search engine. Another strategy is to build a local database of

122 bibliographic data and match citations strings to that database. I used Mendeley

123 (http://www.mendeley.com) to store bibliographic data harvested from journal or taxon-specific

124 web pages in publicly accessible "groups", and then queried the local copy of the Mendeley

125 Desktop database to search for references that matched the citation strings.

126 For the example in Figure 2, the citation string "Description of a new species of Pinnotheres, and-

127 redescription of P. novaezelandiae (Brachyura: Pinnotheridae). New Zealand Journal of Zoology,

128 10(2) 1983: 151-162. 158 (Zoological Record Volume 120)" corresponds to the article with the-

129 DOI 10.1080/03014223.1983.10423904. Onee we have a DOI, we ean then use serviees sueh as

130 those provided by CrossRef (http://www.erossref.org) to retrieve author and publisher

131 information for an artiele (see Fig. 11 below for one use of publisher information).

132 Identifiers also exist for aggregations of publications, such as journals. The historical practice of

133 abbreviating journal titles in citations has led to a plethora of ways to refer to the same journal.

134 For example, the BioStor database (http://biostor.org; Page 2011b) has accumulated more than

135 ten variations on the name of the journal Bulletin of Zoological Nomenclature (such as "Bull Zool

136 Nomen", "Bull Zool Nom.", "Bull. Zool. Nomencl.", etc.). This practice, presumably motivated

137 by the desire to conserve space on the printed page, complicates efforts to match citations to

138 identifiers. One approach to tackling this problem is to map abbreviations to journal-level 
139 globally unique identifiers, such as International Standard Serial Numbers (ISSNs) (for the

140 Bulletin of Zoological Nomenclature the ISSN is 0007-5167). In addition to reducing ambiguity,

141 there are web services such as that provided by WorldCat (http://www.worldcat.org) that take

142 ISSNs and return the history of name changes for a journal, which in turn can help clarify the

143 (often complicated) history of long-lived journals-. Where possible each journal in BioNames

144 was associated with its corresponding ISSN. If an ISSN is not available for a journal, then the

145 corresponding OCLC Control Number was used as the identifier for the journal.

146 Documents

147 Taxonomic publications are available under a variety of licenses, ranging from explicitly open

148 access licenses (MacCallum 2007) to articles that are "free", to articles that are behind a paywall.

149 Archives such as JSTOR and CiNii have a mixture of free and subscription-based content. Many

150 smaller journals, often published by scientific societies, are providing their content online for

151 free, if not explicitly under an open license. The Biodiversity Heritage Library (the single largest

152 source of taxonomic articles in BioNames, Fig. 11) makes its content available under a Creative

153 Commons license. Where PDFs were available online either "for free" or under open access,

154 these were downloaded and locally cached. Pages were extracted and converted into bitmap

155 images for subsequent display in a web browser.

156 Closed-access publications that are available online are linked to by their identifier (e.g., DOI).

157 Access to some of these publications may be available for short-term "rent" by services such as

158 DeepDyve (http://www.deepdyve.com): where possible BioNames includes a link those services. 
160 Taxonomic names comprise a "canonical" name and the name's authorship, for example Homo

161 sapiens Linnaeus comprises the canonical name "Homo sapiens" and the authorship string

162 "Linnaeus". Names in taxonomic databases such as ION display numerous variations in spelling

163 of authors and/or variation in the year of publication, and instances of the same canonical name

164 published by different authors (e.g., homonyms), so the names were clustered before populating

165 BioNames. For each set of taxon names with the same canonical name the authorship was

166 compared. If one name lacked an author and the other had an author, the names were

167 automatically merged into a cluster. Given more than two names a graph was constructed where

168 the nodes are the authorship strings, and a pair of nodes is connected if their corresponding

169 strings were sufficiently similar. String similarity was computed by converting the strings to a

170 "finger print" comprising lower case letters with all accented characters replaced by non-accented

171 equivalents, and all punctuation removed, then finding the longest common subsequence of the

172 two strings. By definition the characters in a common subsequence do not need to be consecutive,

173 so the method allows for insertion and deletion of characters. If the length of the subsequence

174 relative to the each of the two input strings was longer than a specified threshold (by default, 0.8 ,

175 where identical strings have a similarity of 1.0) then the two author strings were connected by an

176 edge in the graph. The components of the graph correspond to clusters of names with similar

177 authorship strings, and were treated as being the same name. Figure 3 shows a graph for the

178 different names that all have "Rhacophorus" as the canonical name.

\section{Mapping names to taxa}


180 BioNames includes two taxonomic classifications, sourced from GBIF

181 (http://uat.gbif.org/dataset/d7dddbf4-2cf0-4f39-9b2a-bb099caae36c) and NCBI

182 (ftp://ftp.ncbi.nih.gov/pub/taxonomy), respectively. These provide the user with a way to navigate

183 through taxonomic names, as well as view data associated with each classification (e.g.,

184 phylogenies). These classifications also provide an explicit definition of the scope of a taxon (i.e.,

185

the "taxon concept"). A higher taxon comprises the set of taxa below that taxon in the

186

classification. A terminal taxon (the lowest taxon in a classification) in GBIF can be defined as

187

the set of occurrences linked to that taxon, a terminal taxon in NCBI can be defined as the set of

188 sequences linked to that taxon.

189 Ideally there would be a one-to-one mapping between a taxonomic name and a taxon, but

190 complications often arise. In addition to the well-known problems of synonymy (more than one

191 name for the same taxon) and homonymy (the same name used for different taxa), name and

192 taxon databases may store slightly different representations of the same name. For example, ION

193 has four records for the name "Nystactes" (each name is followed by its LSID):

194 Nystactes

195 Nystactes Bohlke

196 Nystactes Gloger 1827

197 Nystactes Kaup 1829 urn:1sid:organismnames.com:name:2787598

urn:1sid:organismnames.com:name:2735131

urn:1sid:organismnames.com:name:4888093

urn:1sid:organismnames.com:name:4888094

198 GBIF has three taxa with this name (the number is the GBIF species id):

199 Nystactes Böhlke, $1957 \quad 2403398$ 
201 Nystactes Kaup, 1829

3239722

202 Note the differences in the name string ("o" versus "ö" in "Böhlke", presence or absence of years

203 and commas). To automate the mapping of names to concepts in cases like this I constructed a

204 bipartite graph where the nodes are taxon names, divided into two sets based upon which

205 database they came from (e.g., one set of names from ION, the other from GBIF). I then connect

206 the nodes of the graph by edges whose weights are the similarity of the two strings computed

207 using the longest common subsequence that the two strings share. For example, Figure 4 shows

208 the graph for "Nystactes", where the nodes corresponding to ION names are enclosed in ovals,

209 and the names from GBIF are enclosed in rectangles. Computing the maximum weighted

210 bipartite matching of this graph creates a map between the two sets of names. Ideally GBIF

211 should have only one entry for Nystactes because each animal name (with a few exceptions) must

212 be unique. If a newer name has already been published before, then it should be replaced by a

213 new name. In this case, Nystactes (Böhlke 1957) has since been replaced by Nystactichthys

214 (Böhlke 1958), and Nystactes (Kaup 1829) by Paramyotis (Bianchi 1916). Unfortunately these

215 changes have not yet percolated their way from the primary literature into the GBIF taxonomy.

216 Images

217 To help the user recognise the taxa being displayed images for as many taxa as possible were

218 obtained using EOL's API, which provides access to both the images, and a mapping between

219 GBIF and NCBI taxon concept identifiers and the corresponding record in EOL. 
221 Phylogenies were obtained from the PhyLoTA database (http://phylota.net) (Sanderson et al.

222 2008). This database contains eukaryote phylogenies constructed from automatically assembled

223 clusters of nucleotide sequences (loosely corresponding to "genes"). A MySQL data dump was

224 downloaded (version 184, corresponding to the GenBank release of the same version number)

225 and used to populate a local MySQL database. Metadata for the sequences in each phylogeny was

226 obtained from the European Bioinformatics Institute (EBI; http://www.ebi.ac.uk), and used to

227 populate the MySQL database with basic information such as taxon and locality information, as

228 well as bibliographic details for the sources of the sequences.

\section{Database}

230 Once aggregated, cleaned, and reconciled, the data was converted to JSON (JavaScript Object

231 Notation) and stored in a CouchDB database. CouchDB is a "NoSQL" document database that

232 stores objects in JSON format. Unlike typical SQL databases, CouchDB does not have a database

233 schema and does not support ad hoc queries. Instead CouchDB accepts semi-structured

234 documents, and the thereveloper defines fixed queries or "views" (Anderson et al. 2010).

\section{Results}

236 BioNames comprises a CouchDB database and a web interface. Key features of the interface are

237 outlined below. 
239 BioNames features a simple search interface that takes a scientific name and returns matching

240 taxonomic names and concepts, together with any publications and phylogenies that contain the

241 name. Figure 5 shows an example search result.

\section{Document display}

243 BioNames uses the DocumentCloud (https://github.com/documentcloud/document-viewer)

244 viewer to display both PDFs, and page images from digital archives such as BioStor and Gallica

245 (http://gallica.bnf.fr/) (Fig. 6).

\section{Journals}

247 Much of the work in populating BioNames comprises mapping citation to string to bibliographic 248 identifiers and, where possible, linking those citations to full text. For each journal that has a

249 ISSN, BioNames has a corresponding web page that lists all the articles from that journal that are

250 in the database, and provides a graphical summary of how many of those articles have been 251 located online (Fig. 7).

\section{Timeline}

253 BioNames can display timelines of the numbers of taxonomic names published in higher 254 taxonomic groups, inspired by Taxatoy (Sarkar et al. 2008) (Fig. 8). For a given node in the 
255 taxonomic hierarchy the children of that node are displayed as a treemap where the size of each

256 cell is proportional to the log of the number of taxa in the subtree rooted on that child taxon. The

257 number of names in that taxon published in each year is displayed as an interactive chart.

258 Clicking on an individual year will list the corresponding publications for that year.

259 Taxa

260 Each GBIF or NCBI taxon in BioNames has a corresponding web page that lists the associated 261 taxonomic names, publications linked to those names, and other relevant data (e.g., Fig. 9).

\section{Phylogenies}

263 Phylogenies from PhyLOTA are rendered in an interactive viewer using the Scalable Vector

264 Graphics (SVG) format. The user can zoom in and out, and change the drawing style. Terminal

265 taxa with the same label have the same colour (Fig. 10). This makes it easier to recognise clusters

266 of sequences from the same taxon (e.g., conspecific samples), as well as highlight possible errors

267 (e.g., mislabelled or misidentified sequences). At present the colours are arbitrarily chosen, other

268 schemes could be added in future (Lespinats and Fertil 2011).

269 Dashboard

270 The BioNames web site features a "dashboard" which displays various summaries of the data it

271 contains. For example, Fig. 11 shows a bubble chart of the number of articles different publishers

272 have made available online. "Publisher" in this context is broadly defined to include digital 
273 archives such as BioStor and JSTOR, repositories using DSpace, and commercial publishers such

274 as Elsevier, Informa UK, Magnolia Press, Springer, and Wiley. 
276 The EOL Computational Data Challenge imposed a deadline on the first release of BioNames,

277 however development of both the database and web interface is ongoing. Below I discuss some 278 potential applications and future directions.

279 Links

280 BioNames makes extensive use of identifiers to clean and link data, but the real value of

281 identifiers becomes apparent when they are shared, that is, when different databases use the same

282 identifiers for the same entities, instead of minting their own. Reusing identifiers can enable

283 unexpected connections between databases. For example, the PubMed biomedical literature

284 database has a record (PMID:948206) for the paper "Monograph on 'Lithoglyphopsis' aperta, the

285 snail host of Mekong River Schistosomiasis" (Davis et al. 1976). The PubMed record contains

286 the abstract for the paper, but not a link to where the user can obtain a digital version of the paper.

287 However, this reference is in a volume that has been scanned by the Biodiversity Heritage

288 Library, and the article has been extracted by BioStor (http://biostor.org/reference/102054). If

289 PubMed was linked to BHL, users of PubMed could go straight to the content of the article. But

290 this is just the start. The Davis et al. paper also mentions museum specimens in the collection of

291 the Academy of Natural Sciences of Drexel University, Philadelphia. Metadata for these

292 specimens has been aggregated by GBIF, and the BioStor page for this article displays those links

293 (http://biostor.org/reference/102054). In an ideal world we should be able seamlessly to traverse

294 the path PubMed $\rightarrow$ BioStor $\rightarrow$ GBIF. Likewise, we should be able to traverse the path in the

295 other direction. At present, a user of GBIF simply sees metadata for these specimens and a 
296 locality map. They are unaware that these specimens have been cited in a paper (Davis et al.

297 1976) which demonstrates that the snails host the Mekong River schistosome. This connection

298 would be trivial to make if the reciprocal link was made: GBIF $\rightarrow$ BioStor. Furthermore, a link

299 BioStor $\rightarrow$ PubMed would give us access to Medical Subject Headings (MeSH) for the

300 schistosome paper. Hence we could imagine ultimately searching a database of museum

301 specimens (GBIF) using queries from a controlled vocabulary of biomedical terms (MeSH).

302 Making these connections requires not only that we have digital identifiers, but also that where

303 ever possible we reuse existing identifiers. In practice forging these links can be hard work (Page

304 2011a), and many links may be missing from existing databases (Miller et al. 2009). However, if

305 we restrict ourselves to project-specific identifiers then we stymie attempts to create a network of

306 connected biodiversity data.

307 Text mining

308 Much of the value of a scientific publication lies dormant unless it is accessible to text mining,

309 which requires access to full text. Where possible BioNames stores information on the publisher

310 of each article (Fig. 11), which could then be used to prioritise discussions with publishers on

311 gaining access to full text (Van Noorden 2012). Fortunately, the single largest "publisher" of

312 content in BioNames is BioStor (Page 2011b), which contains scans and OCR text from the

313 Biodiversity Heritage Library. BHL makes its content available under a Creative Commons

314 license, and so can be readily mined. Indeed, the text has already been indexed by tools that can

315 recognise taxonomic names (Akella et al. 2012). 
317 The taxonomic community has long felt disadvantaged by the role of citation-based "impact

318 factor" in assessing the importance of taxonomic research (Garfield 2001; Krell 2000; Werner

319 2006) especially as much of the taxonomic literature appears in relatively low-impact journals. A

320 common proposal is to include citations to the taxonomic authority for every name mentioned in

321 a scientific paper (Wägele et al. 2011). Regardless of the merits of this idea, in practice these

322 citations are often hard to locate, which is another motivation for BioNames.

323 There is additional value in surfacing identifiers for the taxonomic literature. In addition to

324 helping construct citation networks, global identifiers can facilitate computing other measures of

325 the value of a taxonomic paper. There is a growing interest in additional measures of post-

326 publication impact of a publication in terms of activity such as social bookmarking, and

327 commentary on web sites ("alt-metrics") (Yan and Gerstein 2011). Gathering these metrics is

328 greatly facilitated by using standard bibliographic identifiers (otherwise, how do we know

329 whether two commentators are discussing the same article or not?). If taxonomic literature is be

330 part of this burgeoning conversation then it needs to be able to be identified unambiguously.

\section{Dark taxa}

332 One of the original motivations for constructing BioNames is the rise of "dark taxa" in genomics

333 databases (Page 2011c). These are taxa that have been sequenced and added to GenBank, but

334 which lack formal Linnaean names. Typically they will have a name that comprises a genus name

335 and some combination of letters and numbers to make the name unique within GenBank (e.g. a 
337 It is clear that some dark taxa do, in fact, have names. For example, consider the frog

338 "Gephyromantis aff. blanci MV-2005" (NCBI taxonomy id 321743), which has a single DNA

339 sequence AY848308 associated with it. This sequence was published as part of a DNA barcoding

340 study (Vences et al. 2005). If we enter the accession number AY848308 into Google we find two

341 documents, one the supplementary table for (Vences et al. 2005), the other a subsequent paper

342 (Vences and Riva 2007) that describes the frog with this sequence as a new species,

343 Gephyromantis runewsweeki. This example is relatively straightforward, but it still required

344 significant time to track down the species description. A key question facing attempts to find

345 names for dark taxa is whether the methods available can be scaled to handle the magnitude of

346 the problem.

347 Alternatively, one could argue that newer technologies such as DNA barcoding make classical

348 taxonomy less relevant, and perhaps the effort in digitising older literature and exposing the

349 taxonomic names it contains is misplaced. A counter argument would be that the taxonomic

350 literature potentially contains a wealth of information on ecology, morphology and behaviour,

351 often for taxa in areas that have been subsequently altered by human activity. Given the rarity of

352 many taxa (Lim et al. 2011), and the uneven taxonomic and geographic distribution of taxonomic

353 expertise (May 1998; Gaston and May 1992), for many species the only significant data on their

354 biology may reside in the legacy literature (possibly under a different name (Solow et al. 1995)).

355 As this legacy becomes more accessible through projects such as BHL (and services that build

356 upon that project; Page 2011a) there will be considerable opportunities to mine that literature for

357 basic biological data (Thessen et al. 2012). 
359 Recently some taxonomic journals have begun to mark up taxonomic names and descriptions

360 (Penev et al. 2010), which is a precursor to linking names and data together. But these

361 developments leave open the problem of what these links will point to. If we have a database of

362 all taxonomic names and the associated literature (such as BioNames aims to be for zoological

363 names), then such a database would provide an obvious destination for those links. Indeed,

364 ultimately, we could envisage publishing new taxonomic publications within such a database, so

365 that each new publication becomes simply another document within the database (Gerstein and

366 Junker 2002). In the same way, we could use automated methods to extend the process of tagging

367 names, specimens and literature cited to the legacy literature (Page 2010), so that the entire body

368 of taxonomic knowledge becomes a single interwoven web of names, citations, publications, and 369 data.

370 Availability

371 BioNames is accessible at http://bionames.org. The source code used to build the web site is

372 available on GitHub http://github.com/rdmpage/bionames. Scripts used to fetch, clean, and 373 reconcile the data are archived in http://github.com/rdmpage/bionames-data

\section{Acknowledgements}

375 I thank Ryan Schenk for his work on the BioNames, and Cyndy Parr (EOL) for managing the

376 EOL Computational Challenge and providing helpful feedback on the development of BioNames.

377 Mark Holder and an anonymous reviewer provided detailed and helpful comments on the 
378 manuscript. Some of the ideas in this manuseriptpresented here were first explored in a talk at the

379 "Anchoring Biodiversity Information: From Sherborn to the 21 st century and beyond"

380 symposium held at The Natural History Museum, London, October 28th 2011. I thank Ellinor

381 Michel for the invitation to speak at that meeting.

\section{References}

383 Akella, L., Norton, C. N., \& Miller, H. (2012). NetiNeti: discovery of scientific names from text

384 using machine learning methods. BMC Bioinformatics, 13(1), 211. doi:10.1186/1471-

$385 \quad 2105-13-211$

386 Anderson, J. Chris, Jan Lehnardt and Noah Slater (2010). CouchDB: The Definitive Guide. O'Reilly, ISBN: 978-0-596-15589-6

Baird, R. (2010). Leveraging the fullest potential of scientific collections through digitisation.Biodiversity Informatics, 7(2). https://journals.ku.edu/index.php/jbi/article/view/3987

Benson, Dennis A., Ilene Karsch-Mizrachi, Karen Clark, David J. Lipman, James Ostell, and Eric W. Sayers (2012). GenBank. Nucl. Acids Res. (2012) 40 (D1): D48-D53. doi:10.1093/nar/gkr1202 21:xxiii-xxxii (not seen) 
397 Blagoderov, V., Kitching, I., Livermore, L., Simonsen, T., \& Smith, V. (2012). No specimen left 398 behind: industrial scale digitization of natural history collections. ZooKeys, 209(0), 133399 146. doi:10.3897/zookeys.209.3178

400 Bollacker, K., Evans, C., Paritosh, P., Sturge, T., \& Taylor, J. (2008). Freebase. Proceedings of the 401 402 2008 ACM SIGMOD international conference on Management of data - SIGMOD ’08 (p. 1247). Association for Computing Machinery. doi:10.1145/1376616.1376746

403

404 405
Böhlke, J. E. (1957). On the Occurrence of Garden Eels in the Western Atlantic, with a Synopsis of the Heterocongrinae. Proceedings of the Academy of Natural Sciences of Philadelphia, 109: 59-79. http://www.jstor.org/stable/4064494

Böhlke, J. E. (1958). Substitute Names for Nystactes Bohlke and Lucaya Bohlke, Preoccupied. Copeia, 1958(1), 59. doi:10.2307/1439557

Conle, Oskar V, and Frank H Hennemann (2002) Revision of neotropic Phasmatodea: The tribe Anisomorphini sensu Bradley \& Galil 1977: (Insecta, Phasmatodea, Pseudophasmatidae). Spixiana Supplement 28: 1-141. http://biostor.org/reference/118220

Davis GM, Kitikoon V, Temcharoen P (1976) Monograph on "Lithoglyphopsis" aperta, the snail host of Mekong River schistosomiasis. Malacologia 15(2): 241-87. http://biostor.org/reference/102054 
414 Deans, A. R., Yoder, M. J., \& Balhoff, J. P. (2012). Time to change how we describe biodiversity. 415 Trends in Ecology \& Evolution, 27(2), 78-84. doi:10.1016/j.tree.2011.11.007

416 Edwards, J. L. (2000). Interoperability of Biodiversity Databases: Biodiversity Information on 417 Every Desktop. Science, 289(5488), 2312-2314. doi:10.1126/science.289.5488.2312)

418 Faulkes, C. G., Bennett, N. C., Cotterill, F. P. D., Stanley, W., Mgode, G. F., \& Verheyen, E. 419 (2011). Phylogeography and cryptic diversity of the solitary-dwelling silvery mole-rat, genus *Heliophobius* (family: Bathyergidae). (A. Kitchener, Ed.)Journal of Zoology, 285(4), 324-338. doi:10.1111/j.1469-7998.2011.00863.x

422

Franz, N. M., \& Cardona-Duque, J. (2013). Description of two new species and phylogenetic reassessment of Perelleschus O’Brien \& Wibmer, 1986 (Coleoptera: Curculionidae), with a complete taxonomic concept history of Perelleschus sec. Franz \& Cardona-Duque, 2013

426 . Systematics and Biodiversity, 11(2), 209-236. doi:10.1080/14772000.2013.806371

427 Garfield, E. (2001).Nature, 413(6852), 107-107. doi:10.1038/35093267

428 Gaston, K. J., \& May, R. M. (1992). Taxonomy of taxonomists. Nature, 356(6367), 281-282. 429 doi:10.1038/356281a0

430 Gerstein, M. and Jochen Junker (2002). Blurring the boundaries between scientific 'papers' and 431 biological databases. Nature http://www.nature.com/nature/debates/e432 access/Articles/gernstein.html 
433 Hebert, P. D. N., Cywinska, A., Ball, S. L., \& deWaard, J. R. (2003). Biological identifications through DNA barcodes. Proceedings of the Royal Society B: Biological Sciences, 270(1512), 313-321. doi:10.1098/rspb.2002.2218

436 Hibbett, D., \& Glotzer, D. (2011). Where are all the undocumented fungal species? A study of 437 Mortierella demonstrates the need for sequence-based classification. New Phytologist, 438 191(3), 592-596. doi:10.1111/j.1469-8137.2011.03819.x

Kaup, J. J., \& Stejneger, L. (1829). Skizzirte Entwickelungs-Geschichte und natürliches System der europäischen Thierwelt : Erster Theil welcher die Vogelsäugethiere und Vögel nebst Andeutung der Entstehung der letzteren aus Amphibien enthält /. Smithsonian Institution Biodiversity Heritage Library. doi:10.5962/bhl.title.63915

Kennedy, J. B., Kukla, R., \& Paterson, T. (2005). Scientific Names Are Ambiguous as Identifiers for Biological Taxa: Their Context and Definition Are Required for Accurate Data Integration (pp. 80-95). Springer-Verlag. doi:10.1007/11530084_8 Taxonomic Classifications. Evolutionary Bioinformatics, 257. doi:10.4137/EBO.S7565

449 Lim, G. S., Balke, M., \& Meier, R. (2011). Determining Species Boundaries in a World Full of 450 Rarity: Singletons, Species Delimitation Methods. Systematic Biology, 61(1), 165-169. 451 doi:10.1093/sysbio/syr030 
452 MacCallum, C. J. (2007). When Is Open Access Not Open Access? PLoS Biology, 5(10), e285.

453 doi:10.1371/journal.pbio.0050285

454 Maddison, D. R., Guralnick, R., Hill, A., Reysenbach, A.-L., \& McDade, L. A. (2012). Ramping 455 up biodiversity discovery via online quantum contributions. Trends in Ecology \& 456 Evolution, 27(2), 72-77. doi:10.1016/j.tree.2011.10.010

457 Martin, S., Hohman, M. M., \& Liefeld, T. (2005). The impact of Life Science Identifier on 458 informatics data. Drug Discovery Today, 10(22), 1566-1572. doi:10.1016/S1359$459 \quad 6446(05) 03651-2$

MAY, R. M. (1988). How Many Species Are There on Earth? Science, 241(4872), 1441-1449. doi:10.1126/science.241.4872.1441

Miller, H., Norton, C. N., \& Sarkar, I. N. (2009). GenBank and PubMed: How connected are 463 they? BMC Research Notes, 2(1), 101. doi:10.1186/1756-0500-2-101

464 Müller-Wille, S., \& Charmantier, I. (2012). Natural history and information overload: The case of 465 Linnaeus. Studies in History and Philosophy of Science Part C: Studies in History and Philosophy of Biological and Biomedical Sciences, 43(1), 4-15. doi:10.1016/j.shpsc.2011.10.021

Nagy, L. G., Petkovits, T., Kovács, G. M., Voigt, K., Vágvölgyi, C., \& Papp, T. (2011). Where is 469 the unseen fungal diversity hidden? A study of Mortierella reveals a large contribution of 

reference collections to the identification of fungal environmental sequences. New Phytologist, 191(3), 789-794. doi:10.1111/j.1469-8137.2011.03707.x

472 Page, R. D. M. (1983). Description of a new species of Pinnotheres, and redescription of P. 473 novaezelandiae (Brachyura: Pinnotheridae). New Zealand Journal of Zoology, 10(2), 474 151-162. doi:10.1080/03014223.1983.10423904

Page, R. D. M. (2008a). Biodiversity informatics: the challenge of linking data and the role of 476 shared identifiers. Briefings in Bioinformatics, 9(5), 345-354. doi:10.1093/bib/bbn022

Page, R. D. (2008b). LSID Tester, a tool for testing Life Science Identifier resolution services. 478 Source Code for Biology and Medicine, 3(1), 2. doi:10.1186/1751-0473-3-2

Page, R. D. (2009). bioGUID: resolving, discovering, and minting identifiers for biodiversity 480 informatics. BMC Bioinformatics, 10(Suppl 14), S5. doi:10.1186/1471-2105-10-S14-S5

481 Page, R. D. M. (2010). Enhanced display of scientific articles using extended metadata. Web 482 483 Semantics: Science, Services and Agents on the World Wide Web, 8(2-3), 190-195. doi:10.1016/j.websem.2010.03.004

Page, R. D. M. (2011a). Linking NCBI to Wikipedia: a wiki-based approach. PLoS Currents, 3, 485 RRN1228. doi:10.1371/currents.RRN1228 
486

487

488

489

490

491

492

493

494

495

496

497

Page, R. D. (2011b). Extracting scientific articles from a large digital archive: BioStor and the Biodiversity Heritage Library. BMC Bioinformatics, 12(1), 187. doi:10.1186/1471-2105$12-187$

Page, R. D. M. (2011c). Dark taxa: GenBank in a post-taxonomic world. http://iphylo.blogspot.co.uk/2011/04/dark-taxa-genbank-in-post-taxonomic.html

Page, R. D. M. 2012. EOL Computable Data Challenge. doi 10.6084/m9.figshare.92091

Parr, C. S., Guralnick, R., Cellinese, N., \& Page, R. D. M. (2012). Evolutionary informatics: unifying knowledge about the diversity of life. Trends in Ecology \& Evolution, 27(2), 94103. doi:10.1016/j.tree.2011.11.001

Patterson, D. J., Cooper, J., Kirk, P. M., Pyle, R. L., \& Remsen, D. P. (2010). Names are key to the big new biology. Trends in Ecology \& Evolution, 25(12), 686-691. doi:10.1016/j.tree.2010.09.004

Penev, L., Agosti, D., Georgiev, T., Catapano, T., Miller, J., Blagoderov, V., Roberts, D., et al. (2010). Semantic tagging of and semantic enhancements to systematics papers: ZooKeys working examples. ZooKeys, 50(0). doi:10.3897/zookeys.50.538 
505 Sanderson, M., Boss, D., Chen, D., Cranston, K., \& Wehe, A. (2008). The PhyLoTA Browser:

506 Processing GenBank for Molecular Phylogenetics Research. Systematic Biology, 57(3),

$507 \quad 335-346$. doi:10.1080/10635150802158688

508 Sarkar, I. N. (2007). Biodiversity informatics: organizing and linking information across the 509 spectrum of life. Briefings in Bioinformatics, 8(5), 347-357. doi:10.1093/bib/bbm037

510 Sarkar, I., Schenk, R., \& Norton, C. N. (2008). Exploring historical trends using taxonomic name 511 metadata. BMC Evolutionary Biology, 8(1), 144. doi:10.1186/1471-2148-8-144

512 Schindel DE, Miller SE (2010) Provisional nomenclature: the on-ramp to taxonomic names. In:

513 Polaszek A (Ed) Systema Naturae 250 - The Linnaean Ark. CRC Press, 109-115 pp.

514 Smith, M., Barton, M., Branschofsky, M., McClellan, G., Walker, J. H., Bass, M., Stuve, D., et al. 515 (2003). DSpace. D-Lib Magazine, 9(1). doi:10.1045/january2003-smith

516 Solow, A. R., Mound, L. A., \& Gaston, K. J. (1995). Estimating the Rate of Synonymy.

$517 \quad$ Systematic Biology, 44(1), 93-96. doi:10.1093/sysbio/44.1.93

518 TABERLET, P., COISSAC, E., POMPANON, F., BROCHMANN, C., \& WILLERSLEV, E.

519 (2012). Towards next-generation biodiversity assessment using DNA metabarcoding.

$520 \quad$ Molecular Ecology, 21(8), 2045-2050. doi:10.1111/j.1365-294X.2012.05470.x 
521 Thessen, A. E., Cui, H., \& Mozzherin, D. (2012). Applications of Natural Language Processing in

522 Biodiversity Science. Advances in Bioinformatics, 2012, 1-17. doi:10.1155/2012/391574

523 Van de Sompel, H., \& Beit-Arie, O. (2001). Open Linking in the Scholarly Information

524 Environment Using the OpenURL Framework. D-Lib Magazine, 7(3).

525 doi:10.1045/march2001-vandesompel

526 Van Noorden, R. (2012). Trouble at the text mine. Nature, 483(7388), 134-135.

527 doi:10.1038/483134a

528 Vences M, Riva IDL (2007) A new species of Gephyromantis from Ranomafana National Park, 529 south-eastern Madagascar (Amphibia, Anura, Mantellidae). Spixiana 30(1): 135-143.

530 Vences, M., Thomas, M., van der Meijden, A., Chiari, Y., \& Vieites, D. R. (2005).Frontiers in $531 \quad$ Zoology, 2(1), 5. doi:10.1186/1742-9994-2-5

532 Wägele, H., Klussmann-Kolb, A., Kuhlmann, M., Haszprunar, G., Lindberg, D., Koch, A., \& 533 Wägele, J. W. (2011). The taxonomist - an endangered race. A practical proposal for its 534 survival. Frontiers in Zoology, 8(1), 25. doi:10.1186/1742-9994-8-25

535 Werner, Y. L. (2006). The case of impact factor versus taxonomy: a proposal. Journal of Natural $536 \quad$ History, 40(21-22), 1285-1286. doi:10.1080/00222930600903660 
537 Yan, K.-K., \& Gerstein, M. (2011). The Spread of Scientific Information: Insights from the Web

538 Usage Statistics in PLoS Article-Level Metrics. (A. Vespignani, Ed.)PLoS ONE, 6(5),

539 e19917. doi:10.1371/journal.pone.0019917

540 Zhang, Z.-Q. (2006). The making of a mega-journal in taxonomy. Zootaxa, 1385, 67-68. 


\section{Figure 1}

Taxonomy data model

Simplified diagram of the relationships between the core entities that make up taxonomy, such as authors, publications, taxon names, and taxa. Relationships between entities are represented by lines, those in black are the focus of BioNames.

\section{images}

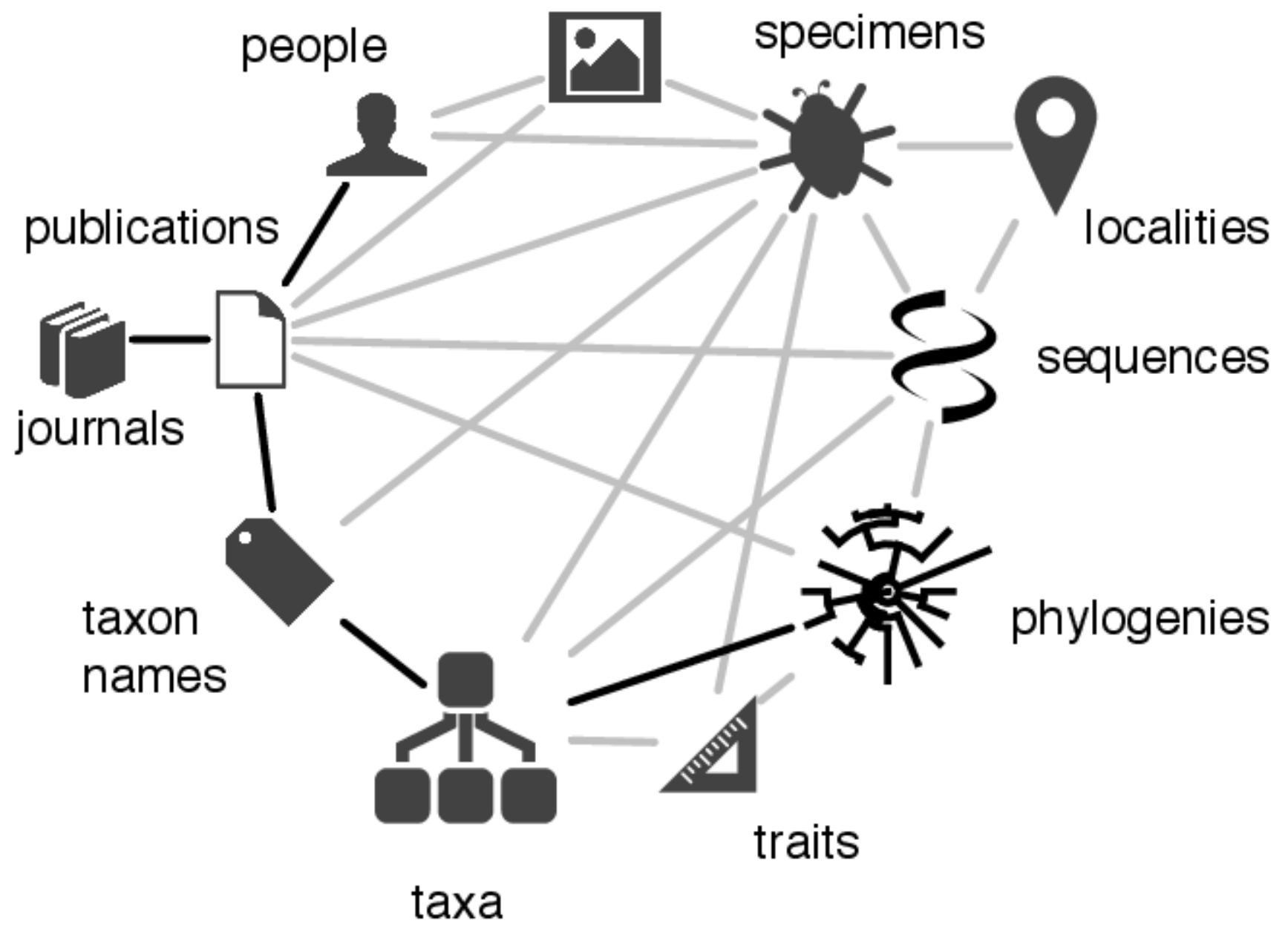




\section{Figure 2}

\section{RDF for taxon name}

The RDF retrieved by dereferencing the LSID urn:Isid:organismnames.com:name:371873, which identifies the taxonomic name Pinnotheres atrinicola.

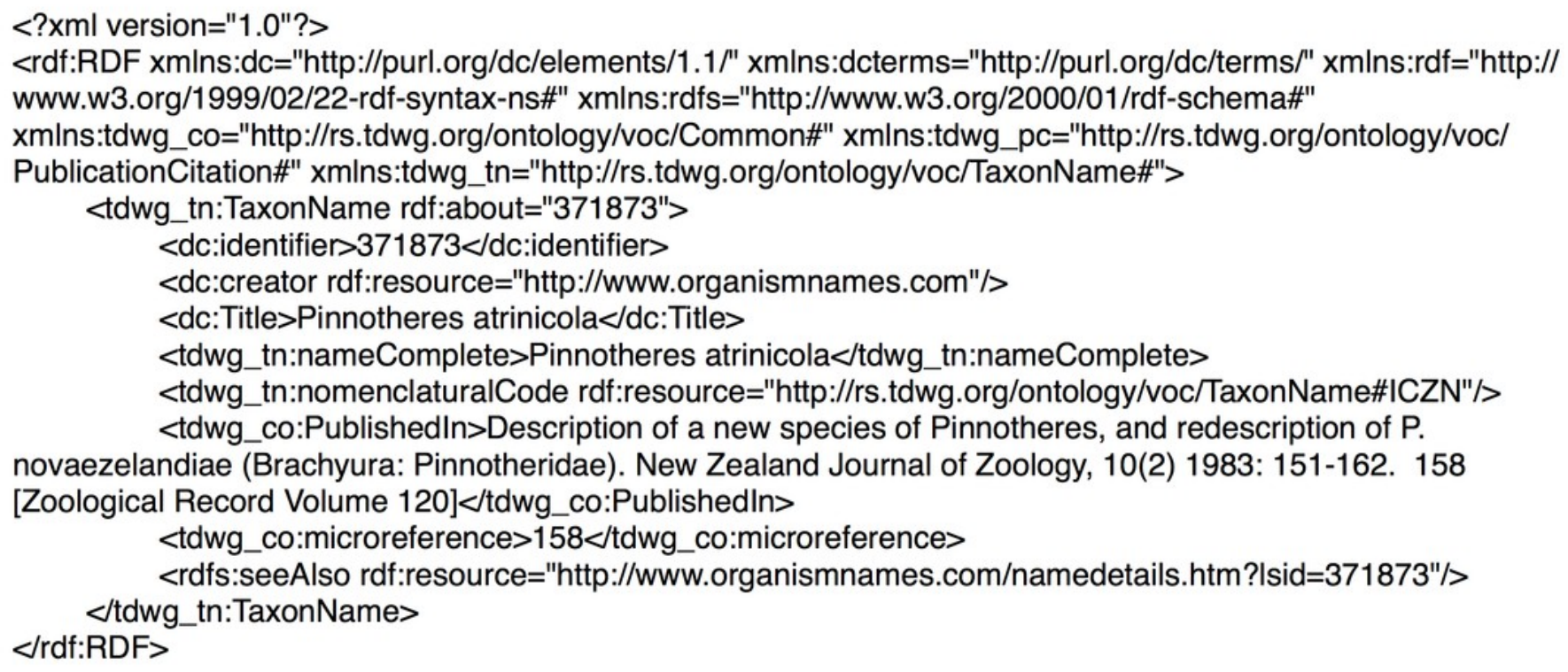




\section{Figure 3}

Clustering taxonomic names

Graph depicting similarity between different authorship strings associated with the name "Rhacophorus". The components of this graph correspond to the name clusters recognised by BioNames.

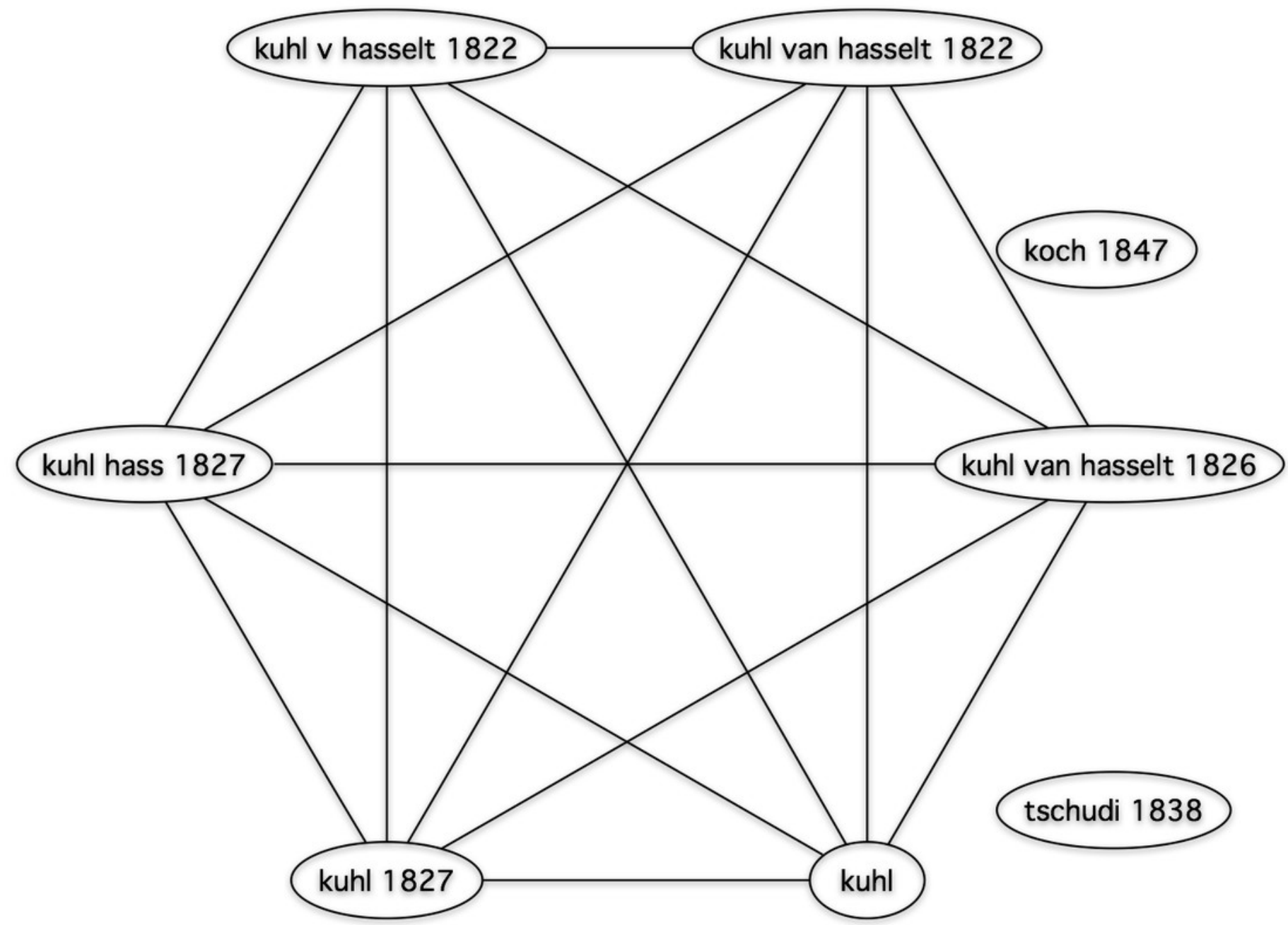




\section{Figure 4}

Matching taxonomic names to taxa

Bipartite graph of string similarities between taxonomic names containing the string "Nystactes" in the ION and GBIF databases. Solid edges in the graph represent the maximum weighted bipartite matching, and define the mapping between ION name (ovals) and GBIF names (rectangles).

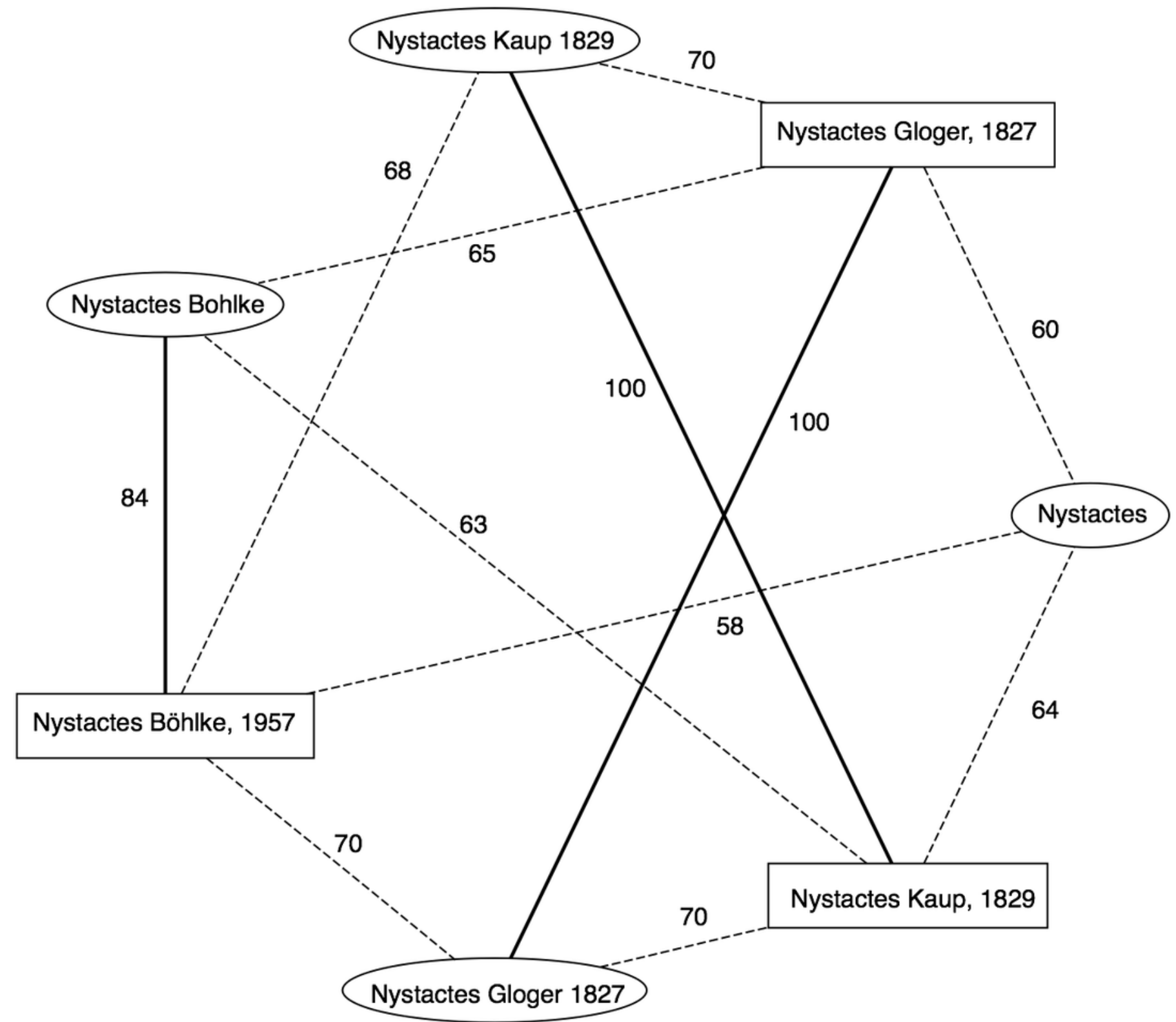




\section{Figure 5}

\section{Search results}

Screenshot of the search results for a query BioNames. The results include names that match the query, taxon concepts from GBIF and NCBI with thumbnail images from EOL, phylogenies containing members of the genus, and relevant taxonomic publications.

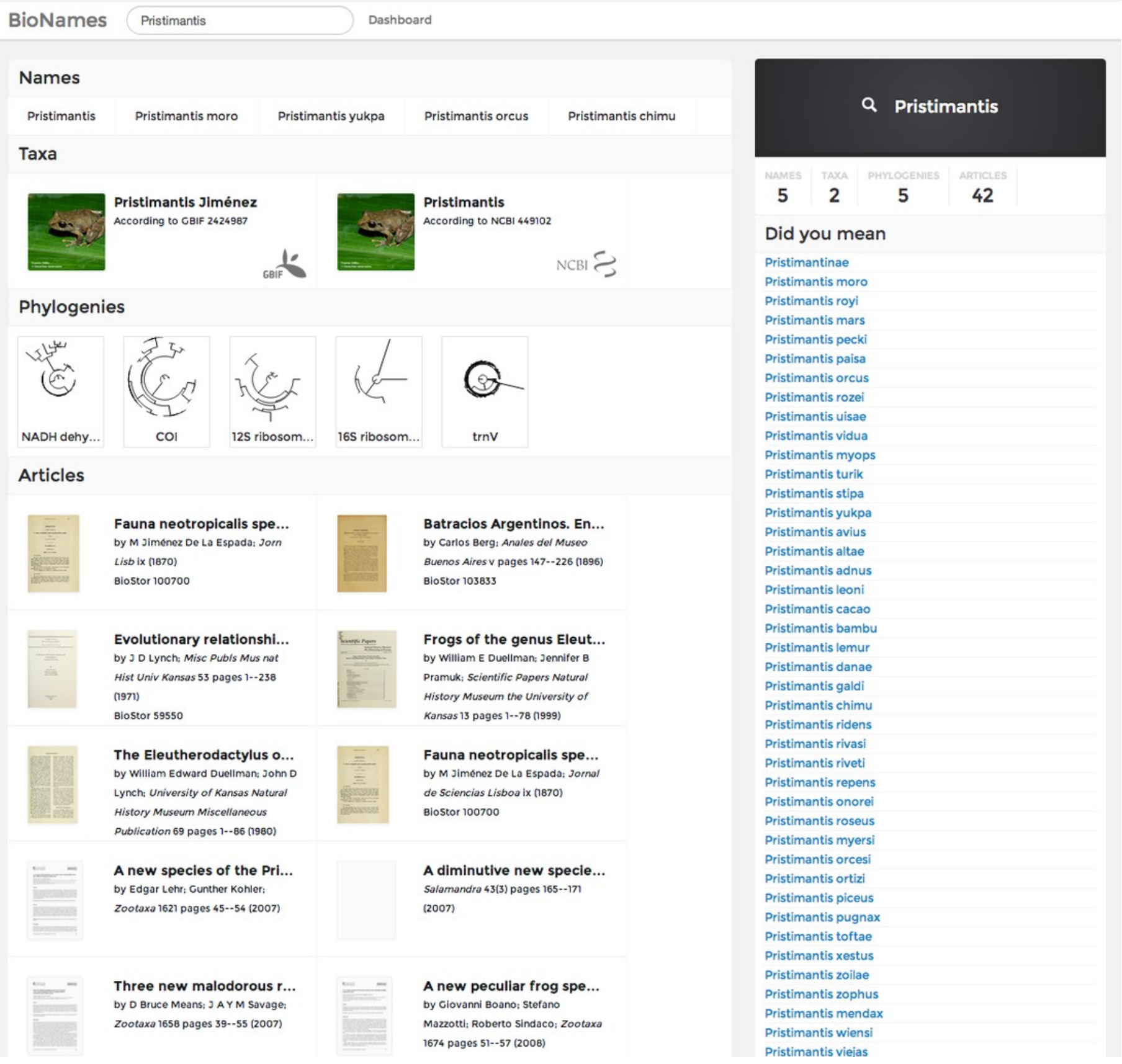




\section{Figure 6}

Displaying an article

Screenshot of BioNames displaying a document from BioStor (Conle and Hennemann 2002).

The document viewer can display page images, thumbnails, and (where available) text.

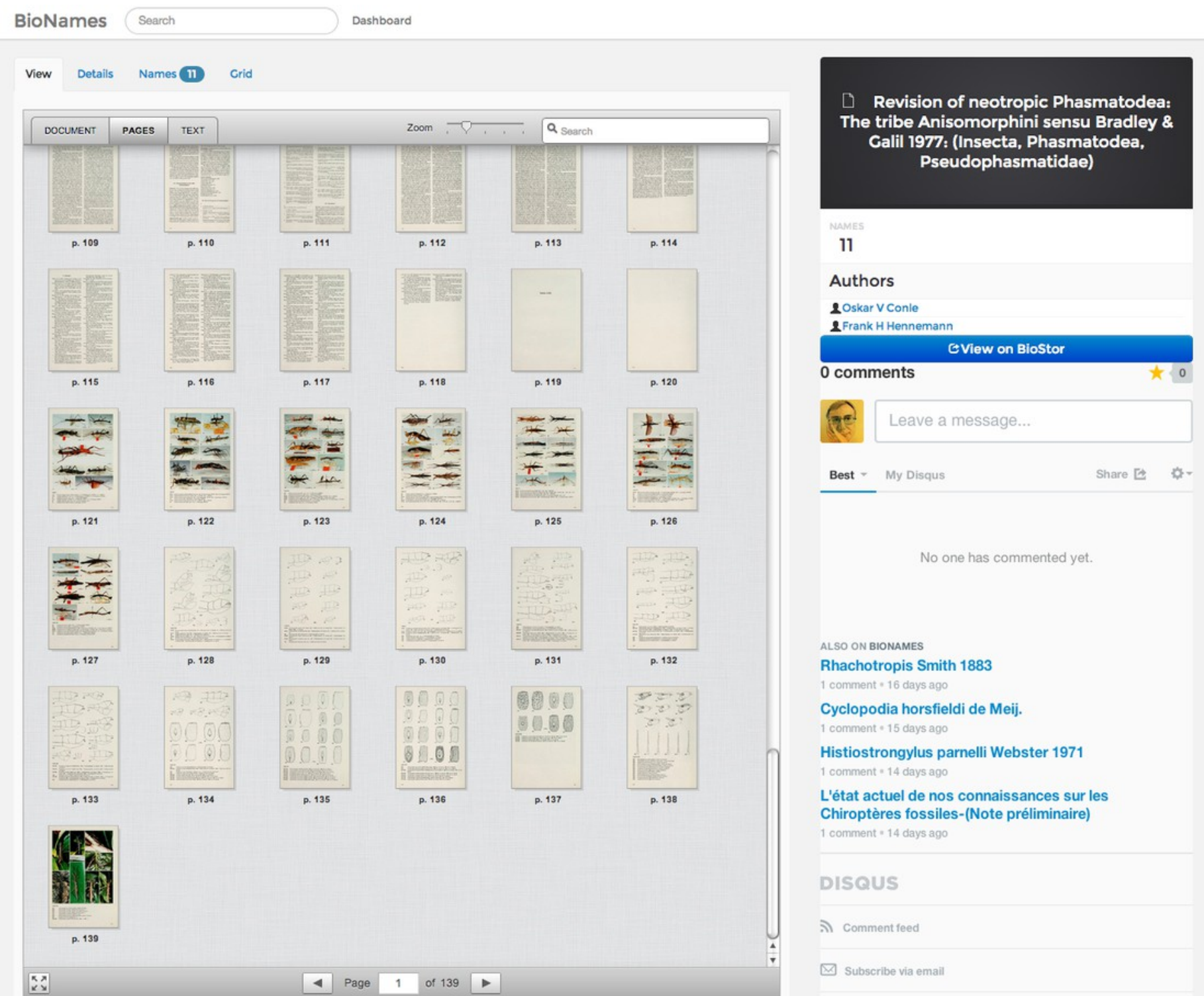




\section{Figure 7}

\section{Displaying a journal}

\section{Screenshot of the page in BioNames for the journal Proceedings of the Entomological}

Society of Washington (ISSN 0013-8797). The centre column lists the articles in a volume

selected by the user using the index on the left. The right hand column displays basic data about the journal, and a graphical display of how many articles have been mapped to a globally unique identifier.

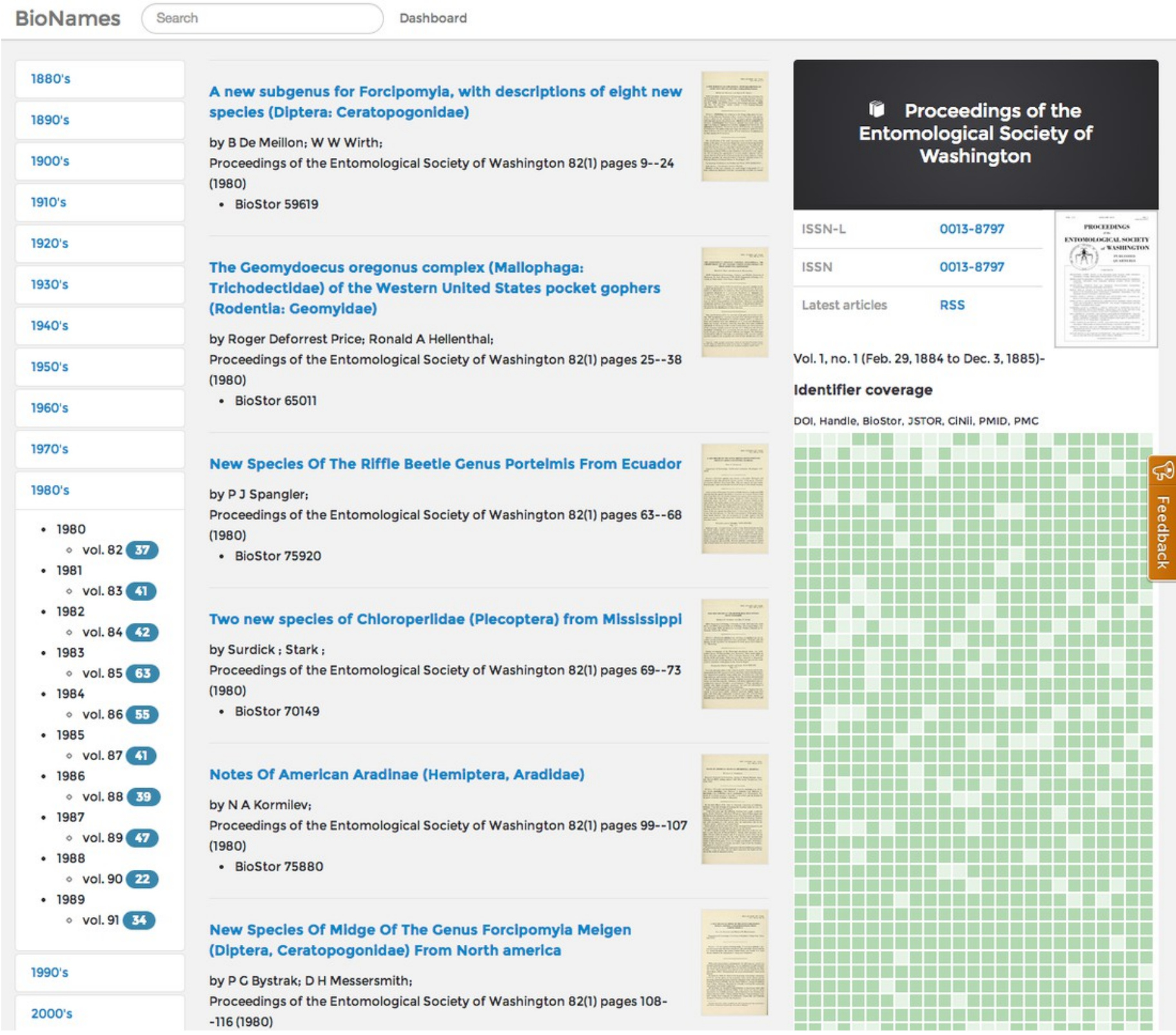




\section{Figure 8}

Timeline of taxonomic names for birds

Screenshot of the distribution overtime of publications of new names for birds (Aves). The treemap on the left displays taxa below Aves in the taxonomic hierarchy, the chart on the right displays the number of publications in each year that publish a new bird name. The user has clicked on "2012", resulting in a list of the papers published in that year appearing below the timeline.

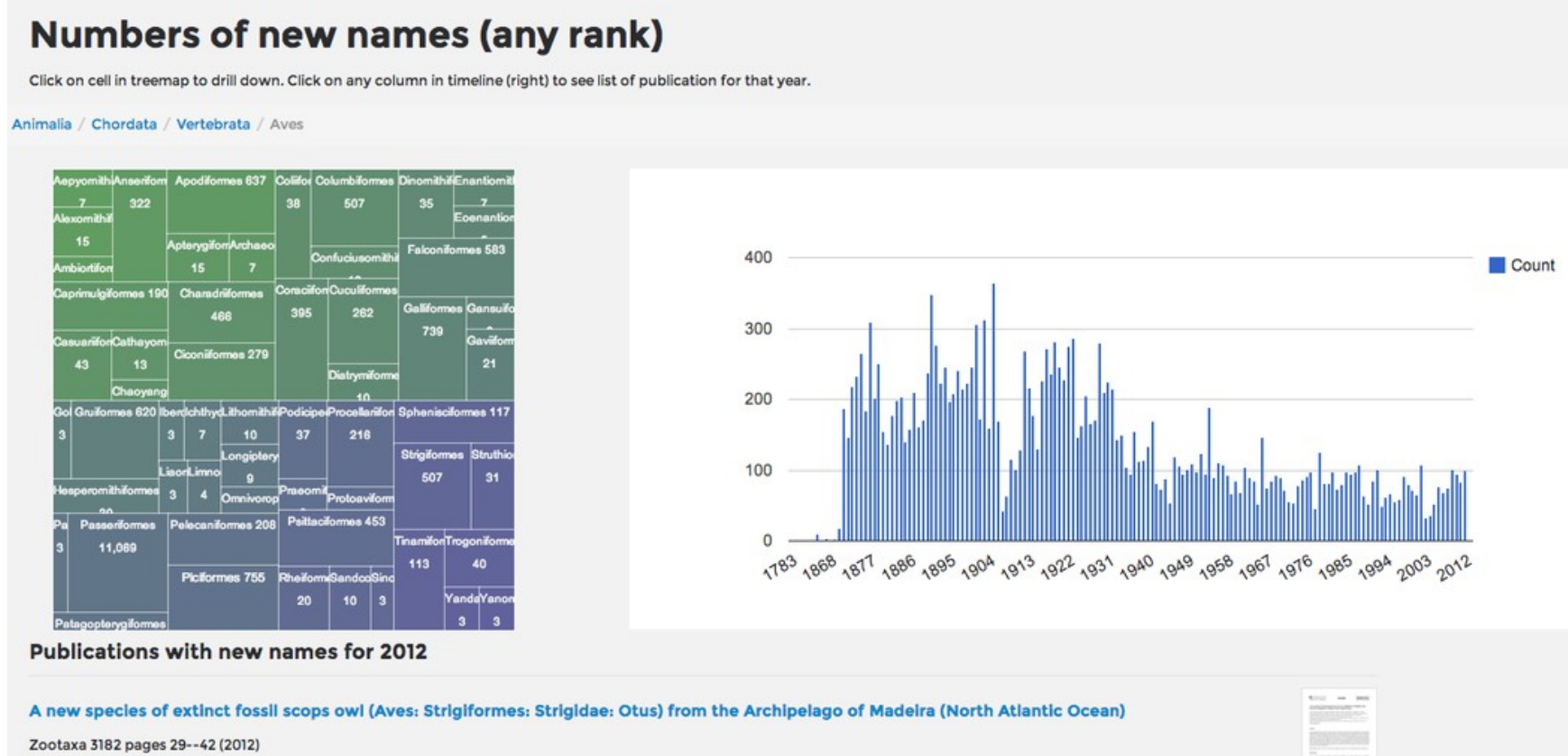

Isleria, a new genus of antwren (Aves: Passeriformes: Thamnophilldae)

by Custavo A Bravo; R Terry Chesser; Robb T Brumfield:

Zootaxa 3195 pages $61--67$ (2012)

A new specles of Jeholornis with complete caudal integument

by Jingmai K O'connor; Chengkai Sun; Xing Xu; Xiaolin Wang; Zhonghe Zhou;

Historical Biology 24(1) pages 29--41 (2012)

- DOI 10.1080/08912963.2011.552720

A revised nomenclature and classiflcation for family-group taxa of parrots (Psittaciformes)

by Leo Joseph; Alicia Toon; Erin E Schirtzinger; Timothy F Wright; Richard Schodde;

Zootaxa 3205 pages 26--40 (2012) 


\section{Figure 9}

\section{Bibliography for a taxon}

Screenshot of the bibliography tab on a taxon page in BioNames. This example shows the publications relevant to the bat genus Rousettus, including those for synonyms. The user can select publications from a given time slice and/or combination of synonyms.

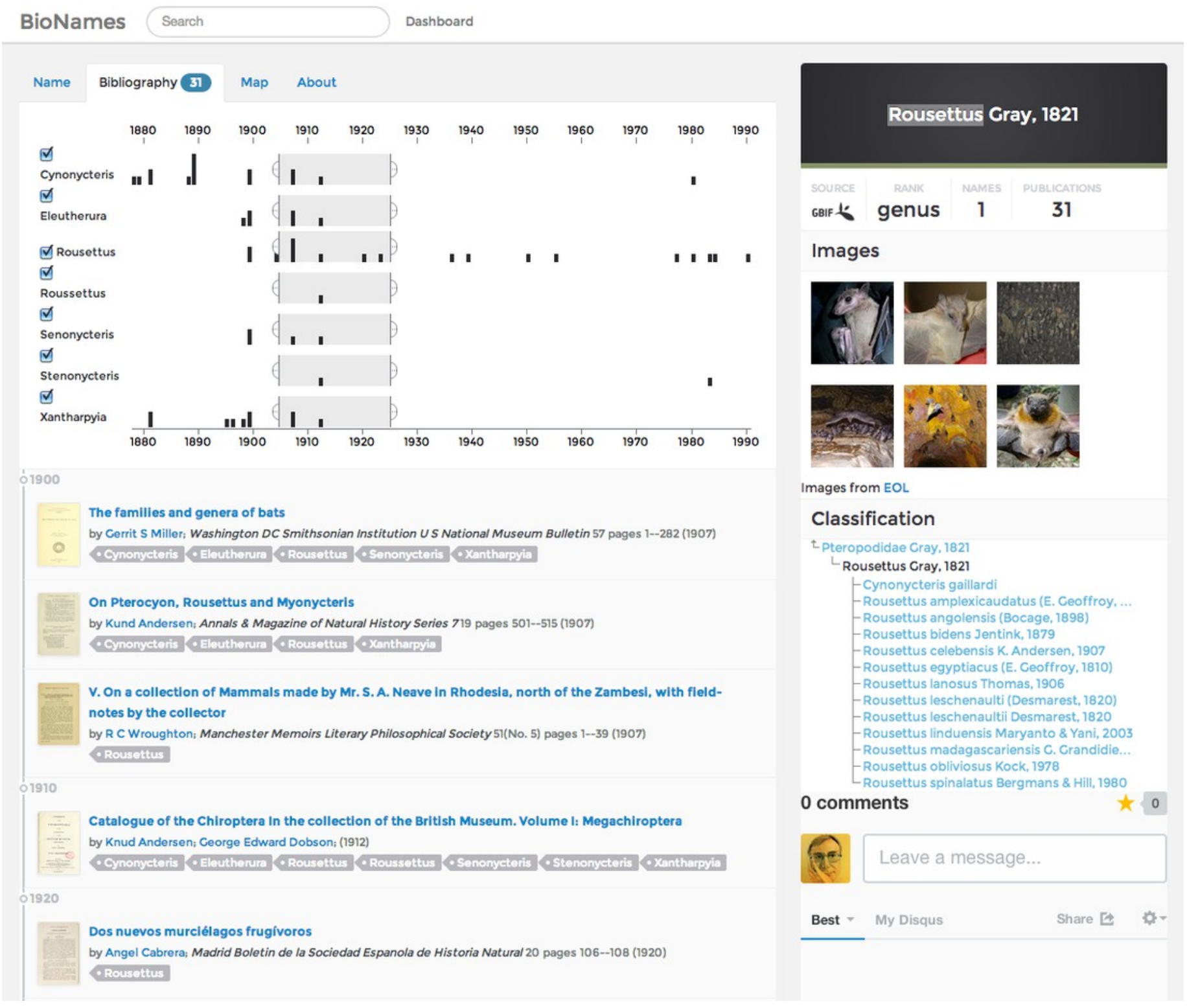




\section{Figure 10}

\section{Phylogeny viewer}

Screenshot of phylogeny from PhyLoTA as displayed in BioNames. The user can zoom in and out and pan, as well as change the layout of the tree.

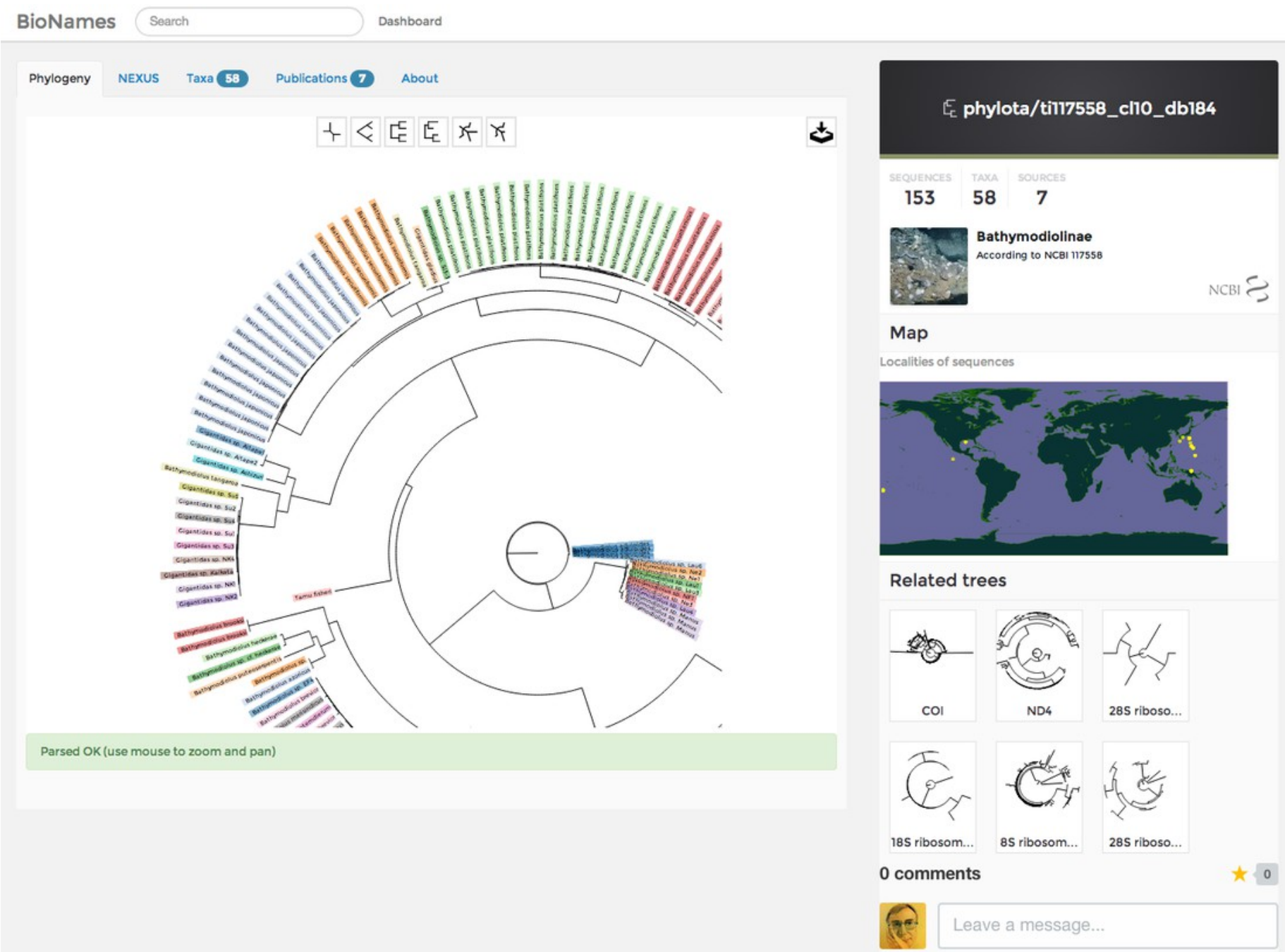




\section{Figure 11}

Relative importance of different publishers of taxonomic literature

Bubble chart showing relative numbers of taxonomic articles made available online by different publishers.

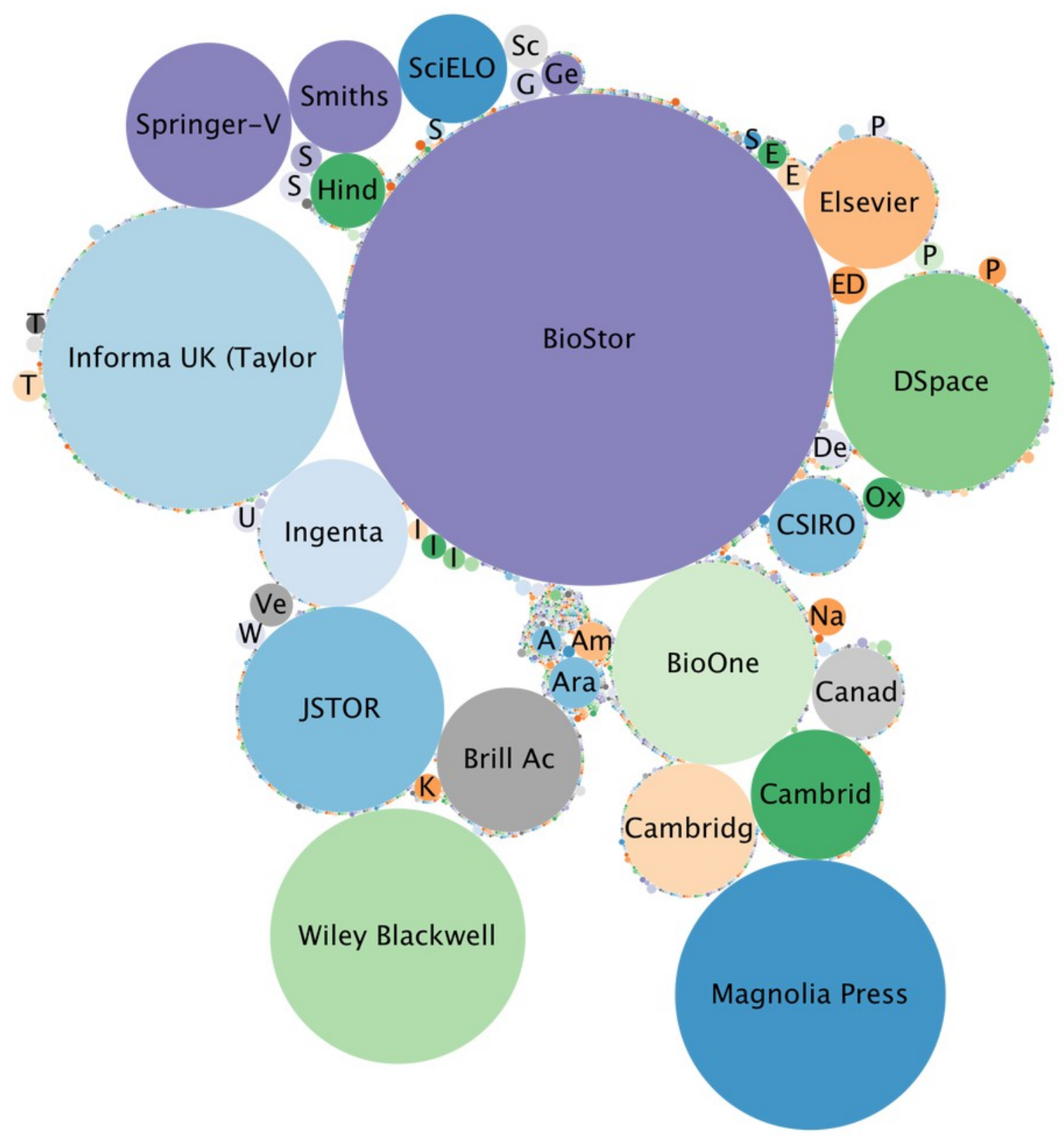

